\title{
Differentiation of live and heat-killed E. coli by microwave impedance spectroscopy
}

Li, Hang; Multari, Caroline; Palego, Cristiano; Ma, Xiao; Du, Xiaotian; Ning, Yaqing; Buceta, Javier; Hwang, James C. M.; Cheng, Xuanhong

\section{Sensors and Actuators B: Chemical}

Published: 01/02/2018

Peer reviewed version

Cyswllt i'r cyhoeddiad / Link to publication

Dyfyniad o'r fersiwn a gyhoeddwyd / Citation for published version (APA):

Li, H., Multari, C., Palego, C., Ma, X., Du, X., Ning, Y., Buceta, J., Hwang, J. C. M., \& Cheng, X. (2018). Differentiation of live and heat-killed $E$. coli by microwave impedance spectroscopy. Sensors and Actuators B: Chemical, 255(Part 2), 1614-1622.

\footnotetext{
Hawliau Cyffredinol / General rights

Copyright and moral rights for the publications made accessible in the public portal are retained by the authors and/or other copyright owners and it is a condition of accessing publications that users recognise and abide by the legal requirements associated with these rights.

- Users may download and print one copy of any publication from the public portal for the purpose of private study or research.

- You may not further distribute the material or use it for any profit-making activity or commercial gain

- You may freely distribute the URL identifying the publication in the public portal ?
}

Take down policy

If you believe that this document breaches copyright please contact us providing details, and we will remove access to the work immediately and investigate your claim. 


\title{
Differentiation of live and heat-killed $E$. coli by microwave impedance spectroscopy
}

\author{
Hang $\mathrm{Li}^{\mathrm{a}}$ \\ Caroline Multaria \\ Cristiano Palego \\ Xiao Mac \\ Xiaotian $\mathrm{Du}^{\mathrm{c}}$ \\ Yaqing Ningc \\ Javier Buceta \\ James C.M. Hwang \\ Xuanhong Chenga., \\ xuc207@lehigh.edu
}

aMaterials Science and Engineering, Lehigh University, Bioengineering Department, PA, U.S.Bethlehem, PA, United States

"School of Electronic Engineering, Bangor University, U.K.Bangor, United Kingdom

'Electrical and Computer Engineering, Lehigh University, PA, U.S.Bethlehem, PA, United States

'Chemical and Biomolecular Engineering, Bioengineering Department, Lehigh University, PA,

U.S.Bethlehem, PA, United States

Corresponding author. Tel.: +1 6107582002 .

\begin{abstract}
The detection of bacteria cells and their viability in food, water and clinical samples is critical to bioscience research and biomedical practice. In this work, we present a microfluidic device encapsulating a coplanar waveguide for differentiation of live and heat-killed E-scherichiacoli cells suspended in culture media using microwave signals over the frequency range of $0.5-\mathrm{GHz}-20 \mathrm{GHz}$. From small populations of $\sim 15 E$. coli cells, both the transmitted $\left(\left|S_{21}\right|\right)$ and reflected $\left(\left|S_{11}\right|\right)$ microwave signals show a difference between live and dead populations, with the difference especially significant for $\left|S_{2 \mid}\right|$ below $10 \mathrm{GHz}$. Analysis based on an equivalent circuit suggests that the difference is due to a reduction of the cytoplasm conductance and permittivity upon cell death. The electrical measurement is confirmed by off-chip biochemical analysis: the conductivity of cell lysate from heat-killed $E$. coli is $8.22 \%$ lower than that from viable cells. Furthermore, protein diffusivity increases in the cytoplasm of dead cells, suggesting the loss of cytoplasmic compactness. These changes are results of intact cell membrane of live cells acting as a semipermeable barrier, within which ion concentration and macromolecule species are tightly regulated. On the other hand, the cell membrane of dead cells is compromised, allowing ions and molecules to leak out of the cytoplasm. The loss of cytoplasmic content as well as membrane integrity areis measurable by microwave impedance sensors. Since our approach allows detection of bacterial viability in the native growth environment, it is a promising strategy for rapid point-of-care diagnostics of microorganisms as well as sensing biological agents in bioterrorism and food safety threats.
\end{abstract}

Keywords: Impedance sensing; Bacterial detection; Cell viability; Biosensor; Microfluidic device; Lab on a chip

\section{Introduction}

Detection of bacteria and their viability in food, water and clinical samples is critically important in fields such as bioscience research, medical diagnosis, food screening and environment monitoring [1]. Conventional methods for bacteria detection, albeit sensitive and specific, are often time-consuming, infrastructure dependent, and require skilled technicians [2]. For example, cell growth-induced turbidity in liquid culture or colony formation on solid culture areis inexpensive and relatively simple to operate, but both require extensive time to generate detectable signals [3,4]. Additionally, cultivation of bacteria is not 
always successful under lab conditions [5]. Fluorescence and colorimetric stains, such as SYTO 9 and propidium iodide (PI), provide viability results in a short time, with established protocols to inspect cell staining by optical microscopy, flow cytometry and microliter plate readers, etc. [6]. However, the labeling procedure is tedious and invasive [6-8]. In addition, the size of bacterial cells is at the detection limit of optical microscopy, making high-resolution imaging difficult [9]. Methods based on nucleic acid amplification are highly sensitive and specific by using target-specific primers to amplify DNA or RNA, however they are destructive and provide little information about cell viability [10,11].

Electrical sensing of cells, including bacteria, is attractive since it is label-free, easy to miniaturize, and offers the possibility of real-time results with high throughput $[12,13]$. Impedance sensing is one of the most popular methods, and has been implemented both for cells adhered to a substrate or in a suspension $[14,15]$. For example, Coulter counters have been widely adopted for cell counting and sizing in a suspension, based on impedance sensing across a pinhole in the $\mathrm{kHz}$ range [16,17]. Microfluidic Coulter counters have been demonstrated by several groups, allowing cell counting and sorting in a portable device [18-21]. Miniaturized impedance sensors using coplanar electrodes have been implemented for monitoring cell proliferation [22], spreading [23,24] and membrane integrity [25], which find applications in basic cell biology research [26] and drug screening [27]. Furthermore, impedance sensing has been used for cell viability detection, including real-time and long-term monitoring of epidermal cell viability [28], cell death induced by viral infection $[29,30]$, chemical toxicity [31] and bacterial metabolism [32,33]. However, most of these impedance sensors are operated using discrete frequencies on the order of $\mathrm{MHz}$ or lower, where solution parasitics are severe and the signal is sensitive to the bulk ion concentration. Double layers on the surface of electrodes limit the voltage drop on target cells and reduce detection sensitivity [34]. The dielectric properties have also been found to depend on many parameters of the cells in this frequency range, so it is hard to attribute the signal change to a single biological parameter using discrete frequencies [35]. Another concern is cell damage by electroporation at such frequencies when the voltage is too high [36-39]. Cell sorting by dielectrophoresis followed with impedance sensing [40], albeit effective to separate live vs. dead cells, requires low-conductivity solutions to promote cell polarization, thus preventing cell detection in their native environment.

Microwave impedance sensing mitigates most of the challenges heretofore mentioned. One of the main advantages is that ion conduction in physiological solutions diminishes [41-44] because ions are too slow to respond at gigahertz frequencies. This facilitates direct cell detection in their native growth environment and extraction of their electrical properties without preparing cells in a low conductive solution. Additionally, transparency of the cell membrane to microwave signals minimizes electroporation and allows interrogation of the cytoplasmic properties, providing complementary information to conventional measurements at radio frequencies. In the past few years, microwave impedance sensors have been implemented by several groups for the detection of biological cells [45-47] and proteins [48]. For instance, Nikolic-Jaric's group detected yeast and mammalian cells within microwave frequencies [45]. Blondy's group reported a biosensor design based on microwave impedance measurements to analyze the growth of different types of adherent cells [46]. Using microchip-based dielectric spectroscopy, Grenier's group characterized dielectric properties of different aqueous solutions [49], biological cell suspensions and a population of adherent cells [47,50-52], and related the measured parameters to cell proliferation and pathogenic states [53]. What's more,-Moutier's group reported using dielectric spectroscopy to detect bacteria proliferation in their native culture environment at a frequency range of 1 - $3 \mathrm{GHz}$ [54]. Recently single--cell dielectric measurements up to $40 \mathrm{GHz}$ hasve also been reported [52]. Furthermore, a model to extract the dielectric parameters has been proposed based on Maxwell's mixture equation [55]. However, most of these studies have limited sensing bandwidth and worked with relative large mammalian cells. In addition, measurement reproducibility was not always confirmed [52]. Many technical challenges are also present for microwave impedance sensing, including impedance match and calibration, circuit modeling and analysis, detection sensitivity in an aqueous environment, and selectivity. Here, we demonstrate for the first time the use of a microwave impedance sensor for reproducible detection of Escherichia coli $E$. colit viability in their native culture media in the frequency range of $0.5-\mathrm{GHz}-20 \mathrm{GHz}$. The microwave coplanar waveguide (CPW) was designed with broadband impedance match and low loss, and integrated with a microfluidic channel for delivering culture media with and without cells [56]. By fitting the measured insertion loss $\left|S_{21}\right|$ and return loss $\left|S_{11}\right|$ to an equivalent circuit, cytoplasmic electrical properties were extracted for small populations of $E$. coli. The difference between live and dead E. coli was confirmed by off-chip measurements of cytoplasm conductivity, permittivity, protein diffusivity and membrane integrity. 


\section{Material \& Mmethods}

\subsection{Bacteria culture and sample preparation}

E. coli strain PHL 628 was cultured overnight in lysogeny broth (LB, Sigma Aldrich, St. Louis, MO) containing $50 \mu \mathrm{g} / \mathrm{mL}$ kanamycin (Sigma Aldrich, St. Louis, MO) in a $37^{\circ} \mathrm{C}$ shaking incubator. The $E$. colisuspension was then centrifuged and washed twice in fresh LB broth. Next $E$. coli was resuspended in fresh LB broth to an $\mathrm{OD}_{600}$ of $3.0\left(2.4 \times 10^{9}\right.$ cells $\left./ \mathrm{mL}\right)$. Corresponding to this OD value, the number of $E$. coli cells in the detection zone was estimated to be $\sim 15$. Samples with lower concentration of cells did not yield signals reproducibly greater than the background.

To deliberately kill $E$. coli, the suspension was placed on a $150{ }^{\circ} \mathrm{C}$ hot plate until its temperature exceeded $75^{\circ} \mathrm{C}$ for $5 \mathrm{~s}$. Afterwards, the E. coli suspension was injected into the microfluidic channel through a syringe pump at a rate of $1 \mu \mathrm{L} / \mathrm{min}$. E. coli viability was verified separately by the LIVE/DEAD FilmTracer fluorescent stain (Invitrogen, Carlsbad, CA). The stain was not used on E. coli that wereas subjected to electrical detection in order to keep the detection label-free. The percentage of viable E. coli cells in ascultured samples wereas found to be $89.57 \% \pm 0.83 \%$, and it dropped to $6.57 \pm 1.65 \%$ in heat-treated samples.

\subsection{Microfluidic device and experimental setup}

The microfluidic device included a poly-dimethyl-siloxane (PDMS, Dow Corning Corporation, Midland, MI) cover clamped on a gold CPW at a 90-degree angle (Fig. 1(ab)) and (b)). The PDMS cover is 5-mm wide, 8-mm long, and 4-mm thick with a molded channel 20- $\mu \mathrm{m}$ deep. PDMS microchannels were fabricated following the standard soft lithography protocol. First SU8 was patterned on a silicon wafer for microchannels with $20 \mu \mathrm{m}$ height. Then a 10:1 mixture of silicone elastomer base and curing agent was poured onto the mold, degassed and cured at $60{ }^{\circ} \mathrm{C}$ overnight. Finally, the PDMS devices were cut out and inlet and outlet ports were punched before attachment to the substrate. The CPW was patterned in 2- $\mu \mathrm{m}-$ thick gold on a 635- $\mu$ m-thick quartz substrate by Applied Thin-Film Products Co. (www.thinfilm.com) using a proprietary process. The center and ground electrodes of the CPW are $40-\mu \mathrm{m}$ and $100-\mu \mathrm{m}$ wide, respectively, with a $10-\mu \mathrm{m}$ spacing in between. We used a custom designed clamp to hold the PDMS microfluidic channel and the substrate together. Since PDMS is compliable, it conforms well to the quartz substrate. In addition, the pressure to drive fluid flow is low, thus no leak was observed during measurements. Reversibly attaching and removing PDMS cover is important in our protocol as we need to clean the substrate and reuse the CPW chip. 


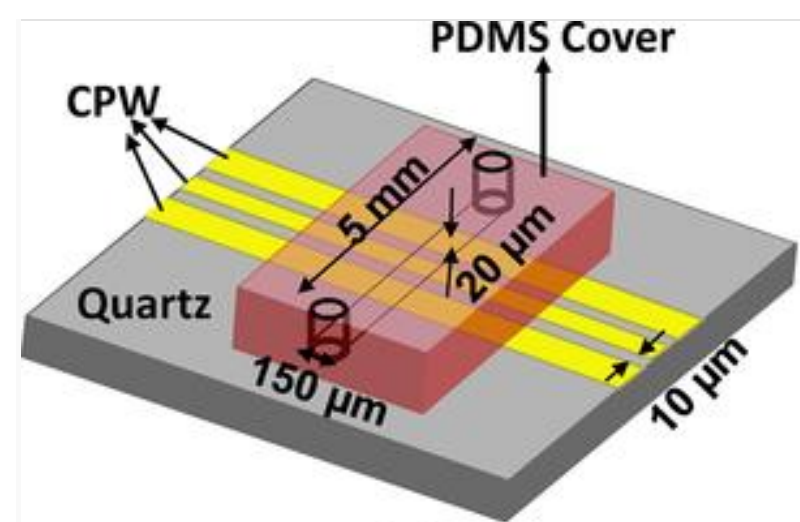

(a)

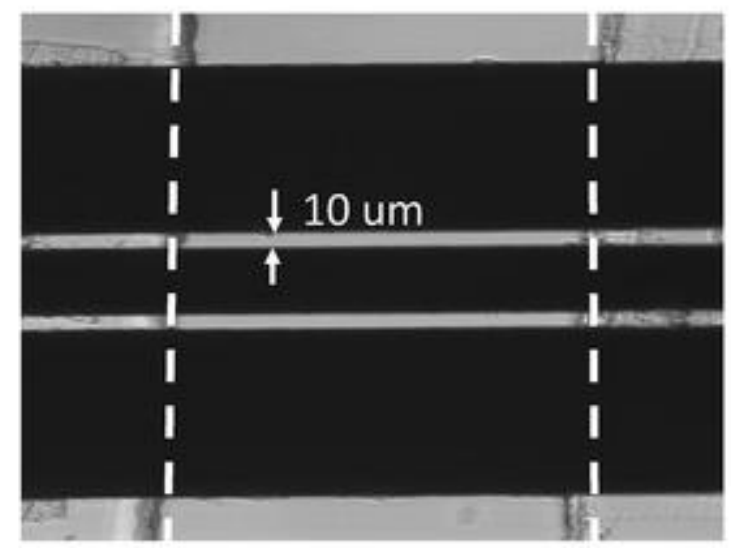

(b)

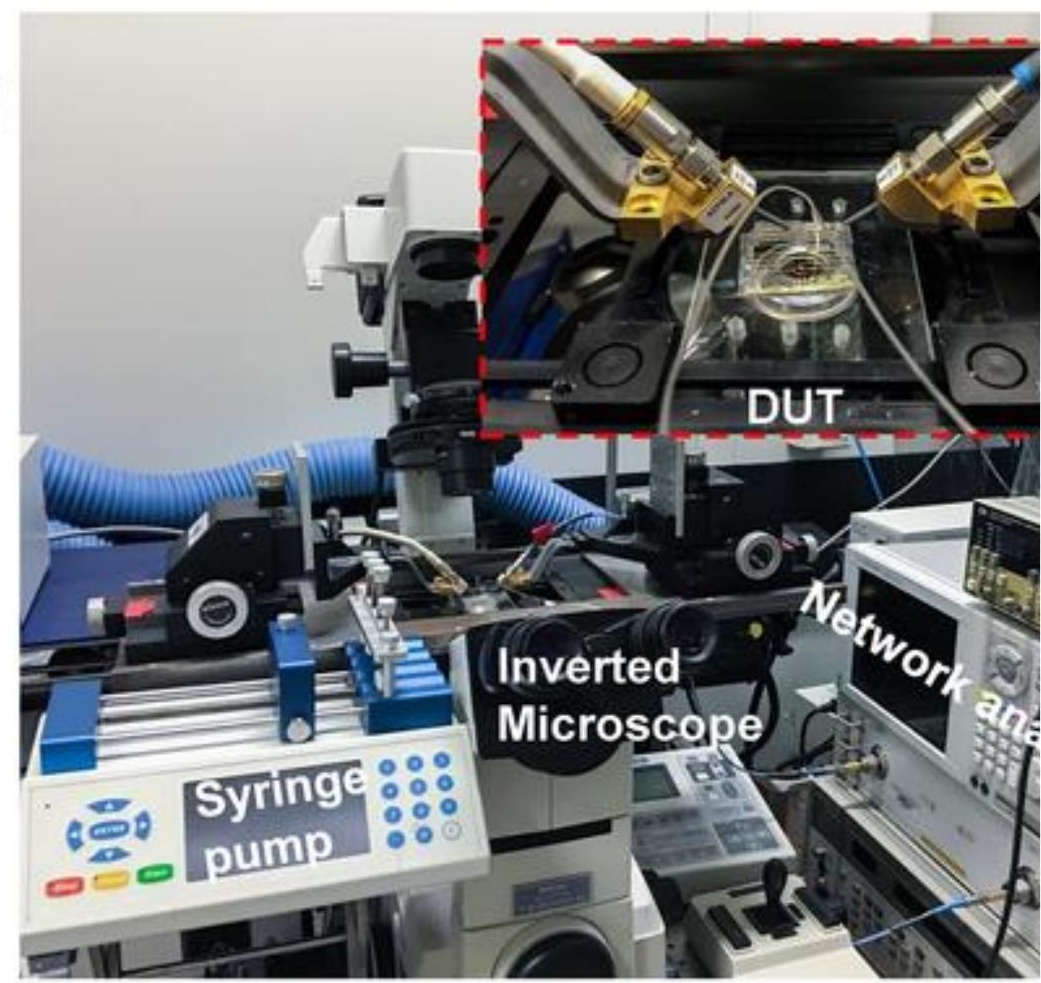

(c)

Figure. 1 (a) A schematic of the device based on a CPW sandwiched between a quartz substrate and a PDMS cover. (b) A micrograph of the device observed under the optical microscope. The three black bands are the electrodes. Dash lines on the sides trace side walls of a transparent microfluidic channel. (c) A photograph showing the experimental setup, containing the test devices connected to a PNA and mounted on an optical microscope. Samples were injected into the device through a syringe pump. The inset shows a zoomed-in picture of the device under test (DUT) interrogated by two microwave manipulators on the microscope stage.

The electrical setup is similar to that for traditional impedance/dielectric spectroscopy measurement, except it uses a thin-film coplanar waveguide (CPW) patterned on a quartz substrate in conjunction with wafer probes (Model ACP40, Cascade Microtech, North St Paul, MN, USA) to improve sensitivity and impedance matching, and a microwave network analyzer (PNA Model 5230A, Agilent Technologies, Santa Clara, CA, USA)) in conjunction with 2-port measurements to expand bandwidth and dynamic range (Fig. 1-(c)). The scattering $(S)$ parameters $|S 21|$ and $|S 11|$ measured on the PNA $(0.5-$ $20 \mathrm{GHz}$ ) in terms of reflection and insertion losses were evaluated. The dielectric constant/conductivity from different cellular compartments wereas extracted from circuit models. The CPW-microchannel assembly was mounted on an inverted microscope to confirm $E$. coli injection and rinsing during the electrical measurement.

\subsection{Electrical measurements on chip}

For each experiment, the microwave background signal was first established by flowing E. colifree LB broth into the microfluidic channel at $1 \mu \mathrm{L} / \mathrm{min}$. The background scattering parameters were measured every $5 \mathrm{~min}$, until they stabilized (change of $\left|S_{11}\right|$ and $\left|S_{21}\right|<0.001 \pm 0.001 \mathrm{~dB}$ within $30 \mathrm{~min}$ ). Thereafter, the $E$. coli suspension was flowed into the microfluidic channel at $1 \mu \mathrm{L} / \mathrm{min}$ for approximately 
30 min. Subsequently, microwave measurements were started and repeated ten times in 5-min intervals. Measurements were considered valid only when the measured scattering parameters were stable within $0.01 \mathrm{~dB}$ among the ten 10 consecutive measurements. The average scattering parameters measured on $E$. coli suspension, after subtracting the previously established background scattering parameters measured on $E$. coli-free LB broth, were deemed $E$. coli signals and were analyzed in the following sections. To validate the measurement and analysis, measurements were repeated on three live E. coli populations and three dead E. coli populations independently. To confirm bacterial concentration does not change significantly during the measurement period, E. coli has been cultured in stereseLB broth solution and measured the $\mathrm{OD}_{600}$ before and after 3 hours(experimental time less than $3 \mathrm{hrs}$ ), the $\mathrm{OD}_{600}$ value did not change.

\subsection{Equivalent circuit model}

Fig. 2(a) shows a schematic model, Fig. 2(c) shows an equivalent circuit model with three sets of CPW transmission lines under infinitely thick air, PDMS, and LB broth, respectively. The characteristic impedance and electrical length of the first two sets of CPW are $Z_{02} \theta_{0}$, and $Z_{1}, \theta_{1}$ respectively. The shunt resistor $R_{01}$ accounts for power dissipation due to impedance mismatch between the first and second sets of CPW.

(a)

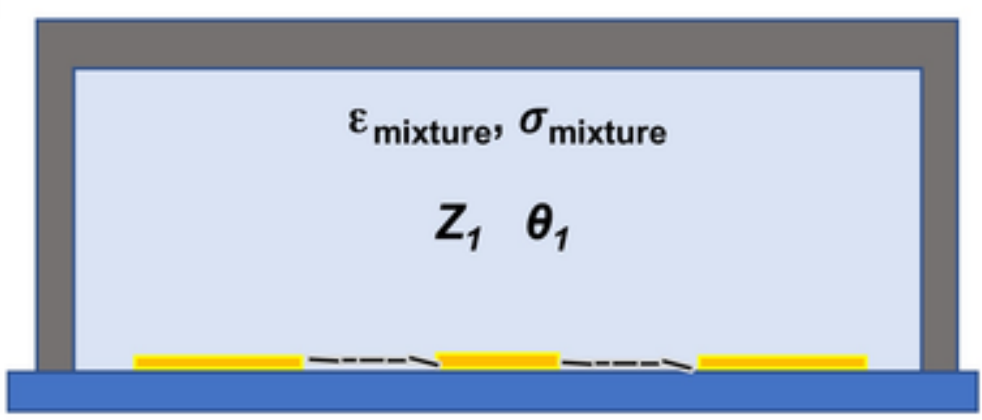

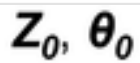

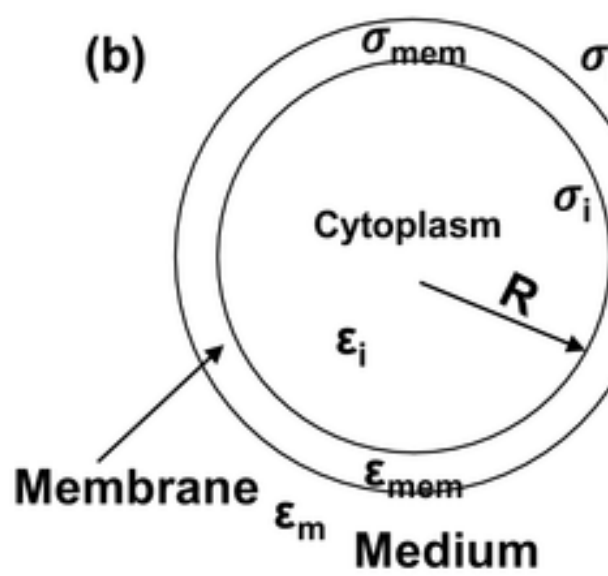

(c)

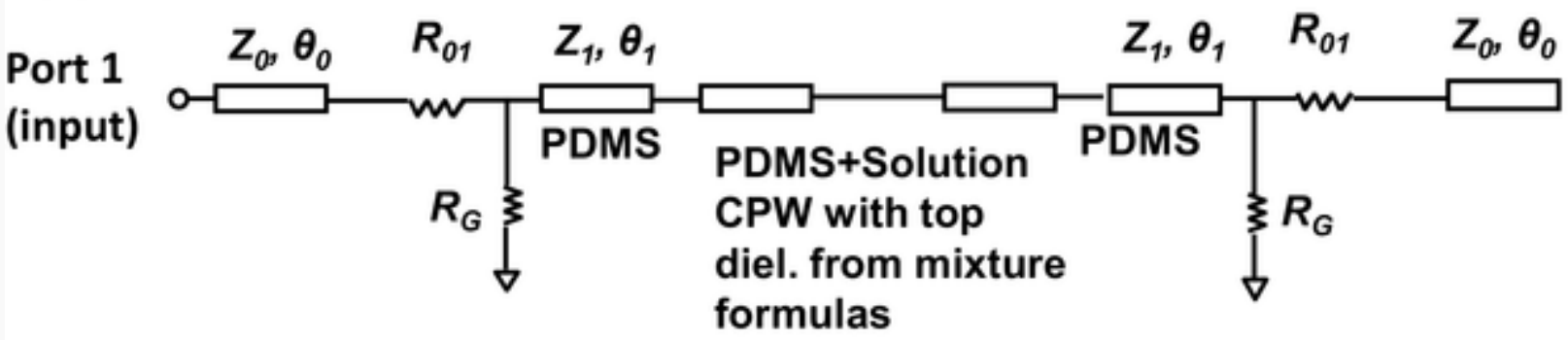

Port 2 (outpu

Figure 2(a) A sehematic-circuit model. 2 (a) A schematic-circuit model. (b) A single shelled spherical particle model used to represent a single $E$. coli cell. (c) The equivalent-circuit model.

The third set of CPW was under the E. coli suspension and its dielectric properties were calculated using Maxwell's mixture theory [55]. TheWith a microchannel height is limited toof $20 \mu \mathrm{m}$, at the top of the channel, the electric field decreased by $80 \%$. This was confirmed by electromagnetic field distribution in the cross section of the fluidic channel through HFSS (Fig. S1). For simplicity E. coli were modeled as singleshelled spherical particles, as shown in Fig. 2-(b) with fractional volume $\varphi$ and radius $R$. $\varphi$ was estimated to be 0.05 and $R$ was $1 \mu \mathrm{m}$. The membrane thickness $d(4 \mathrm{~nm})$ was much smaller than $R$, and the geometrical factor $\gamma=(R+d) / R=1.004$. The $E$. coli cells were modeled as spheres in this study instead of rods or cylinders. This is to reduce computational burden, especially in a context where the measurement accuracy 
is limited. The difference in capacitance or resistance moving from a spherical to a cylindrical or rod shape would be smaller than an order of magnitude, below the experimental noise level. Under these simplifications, a Debye model was assumed for the general complex relative permittivity:

where $x$ in the subscript was replaced by $m$ for the medium, $i$ (internal) for the cytosol and $m e m$ for the membrane. The letter $s$ in the subscript referred to static (low frequency) parameters and $\infty$ referred to high frequency parameters. The mixture permittivity and conductivity were computed as in [55] and entered in the third CPW definition in a circuit simulator environment (Advanced design system (ADS), Keysight, Santa Rosa, CA, USA).

\subsection{Off-chip measurement of lysate permittivity and conductivity of live and dead $E$. coli}

Overnight liquid culture of $E$. coli was first washed and adjusted to $\mathrm{OD}_{600}=3.0$ as described above. The $E$. coli suspension was then split in two. To prepare dead E. coli, the suspension was subjected to heat treatment to deliberately kill the $E$. coli, then washed two times with a low conductive solution that contains $8.5 \%$ sucrose (Sigma-Aldrich, St. Louis, MO) and $0.05 \%$ dextrose (Sigma-Aldrich, St. Louis, MO). Live E. coli were directly washed with the sucrose solution for two times. Afterwards both live and dead $E$. colisamples were lysed with a sonicator probe (Sonic Dismembrator, Fisher Scientific, Waltham, MA, USA). Subsequently, lysate conductivity was measured by a conductivity probe $(\mathrm{CON}+6$ meter $(94 \mathrm{~Hz})$, OAKTON Instruments, Vernon Hills, IL, USA). For permittivity measurements, the dielectric probe (Model 85070 E, Agilent Technologies, Santa Clara, CA, USA) was connected with a network analyzer (Model E5080A, Agilent Technologies, Santa Clara, CA, USA) through an Agilent Electronic Calibration module (Ecal, Model N4691-60006, Agilent Technologies, Santa Clara, CA, USA). The Ecal was also connected to a computer running the $85070 \mathrm{E}$ software, before the measurement calibration was performed. By immersing the dielectric probe in the lysate, the real and imaginary parts of permittivity were directly measured between the frequency ranges of $500 \mathrm{MHz} \_20 \mathrm{GHz}$.

\subsection{Diffusivity of green fluorescence protein (GFP) in the cytoplasm}

Fluorescence recovery after photobleaching (FRAP) was carried out on a Nikon A1Rsi confocal microscope (Nikon, Melville, NY, USA). E. coli strain PHL 628 was transformed with the pAraGFP plasmid to express GFP in the cytosol and the expression was induced by arabinose [57]. The induced E. coli were either used directly or subjected to the heat treatment as described above. A drop of E. coli suspension was pipetted on an agar-coated coverslip and used for the FRAP measurement. A $405 \mathrm{~nm}$ laser pulse sufficient to bleach about half of the $E$. coli was applied for $\sim 0.1$ second $0.1 \underline{\mathrm{s}}$. Then the remaining unbleached GFP was allowed to diffuse and equalize over the entire E. coli, and fluorescence intensity was imaged at 50 frames per second. The videos of the photobleaching and subsequent fluorescence recovery were characterized by measuring the intensity in the bleached portion. GFP diffusivity was extracted by using both the FRAP function in the Nikon AR software, as well as an exponential fit in Origin (Originlab Corporation, Wellesley Hills, MA, USA).

\subsection{Membrane pore size measurements in heat-treated $E$. coli}

E. coli was first killed by heating as described above in Section 2.1. Then a size-exclusion assay was carried out by incubating heat-killed $E$. coli with an anti-ds DNA antibody (ab27156, Abcam, San Francisco, CA, USA) conjugated with streptavidin (ab102921, Abcam, San Francisco, CA, USA). After centrifuging and washing unbound antibodies, the bacteria were incubated with several sizes of biotin-gold nanoparticles (CGB5K-10, CGB5K-20, CGB5K-30, Cytodiagnostics, Burlington, ON, Canada). Subsequently, the E. colicells were stained with Alexa-fluor-546 labeled streptavidin and washed before viewing on agar pads mounted on coverslips by fluorescence microscopy.

\subsection{Statistics}


All experiments were repeated at least 3 times. Statistical analyses were performed using JMP 10 (SAS Institute, Cary NC, USA). Two-tailed Student's $t \underline{t-t e s t s ~ w e r e ~ p e r f o r m e d ~ t o ~ d e t e c t ~ s i g n i f i c a n t ~ d i f f e r e n c e s ~}$ between groups. An $\alpha$ level of 0.05 was used to determine significance between groups.

\section{Results}

\section{1 $S$-parameter measurements from live and dead E. coli}

The $S$-parameters, including the return loss $\left|S_{11}\right|$ and insertion loss $\left|S_{21}\right|$, were measured from E. colifree media and $E$. coli suspensions, respectively. Afterwards, differences in return loss $\left(\Delta\left|S_{11}\right|\right)$ and insertion loss $\left(\Delta\left|S_{21}\right|\right)$ of the $E$. coli suspension from the cell-free media were calculated. The results for live and dead $E$. coli are shown in Fig. 3(a,b)(a) and (b). The number of $E$. coli cells within the detection zone was $\sim 15$, estimated from the cell concentration and volume between the electrode gap. It is observed that although $\Delta\left|S_{11}\right|$ demonstrates different averages between live and dead $E$. coli, the difference is insignificant due to run-to-run variations $(n \underline{n}=3)$. On the other hand, $\Delta\left|S_{21}\right|$ shows a significant difference between live and dead E. coli, especially in the frequency range below $10 \mathrm{GHz}(\nexists \underline{n}=3)$. The insertion loss $\Delta\left|S_{21}\right|$ value also was comparable to previous studies CPW insertion loss measurement results [58,59]. Interestingly, heat-killed $E$. coli yields similar signals to the background for both $\left|S_{11}\right|$ and $\left|S_{21}\right|$, while signals from live bacteria deviate from the background, especially for the insertion loss. This observation suggests that $E$. coli viability can be distinguished by simply comparing the $S$-parameters of the $E$. coli sample to those of athe $E$. coli-free solution, a simple enough procedure potentially operable at the point of need.

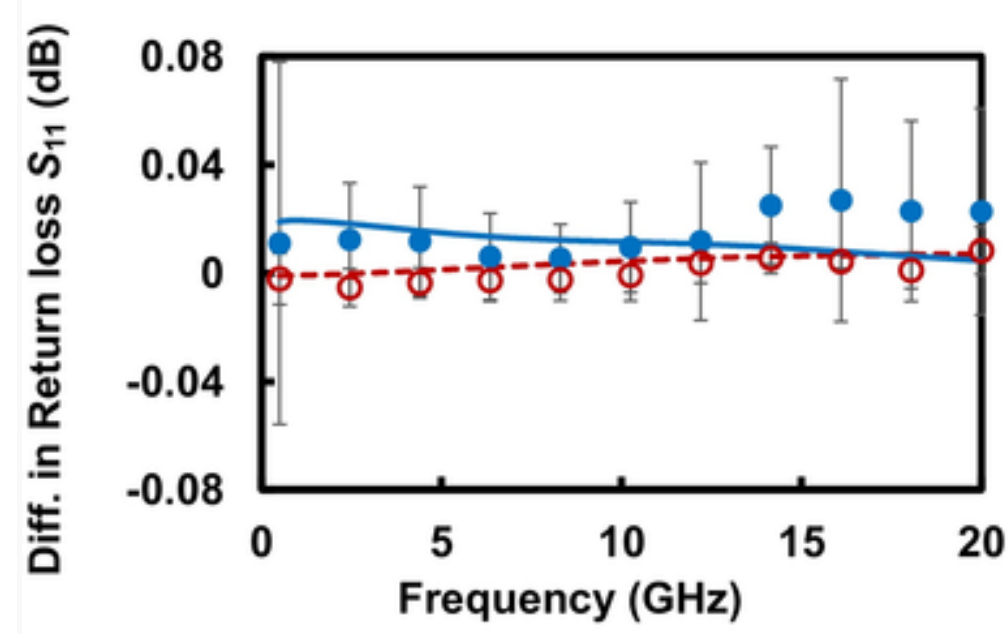

(a)

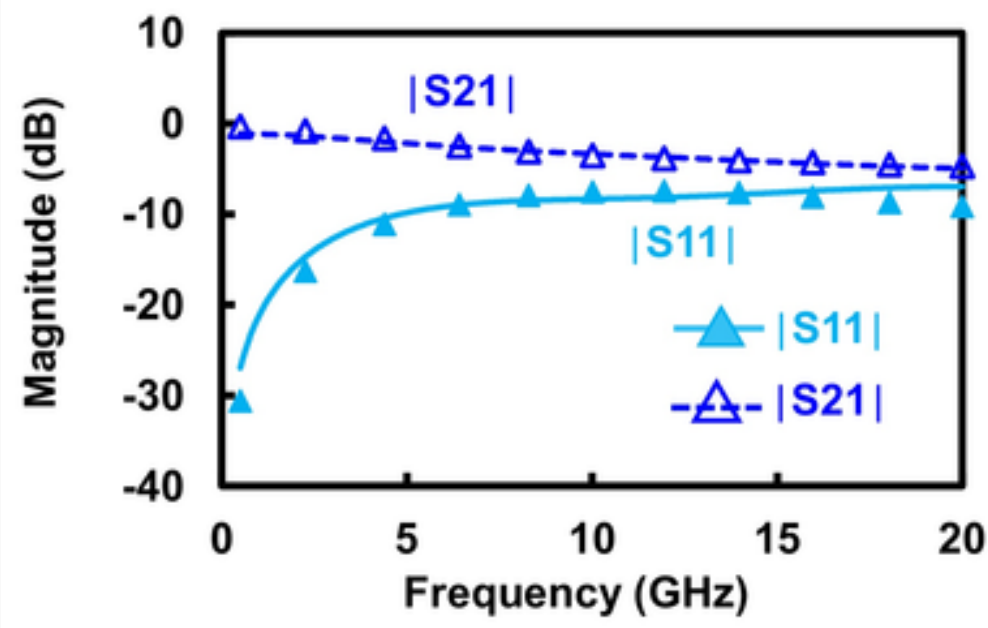

(c)

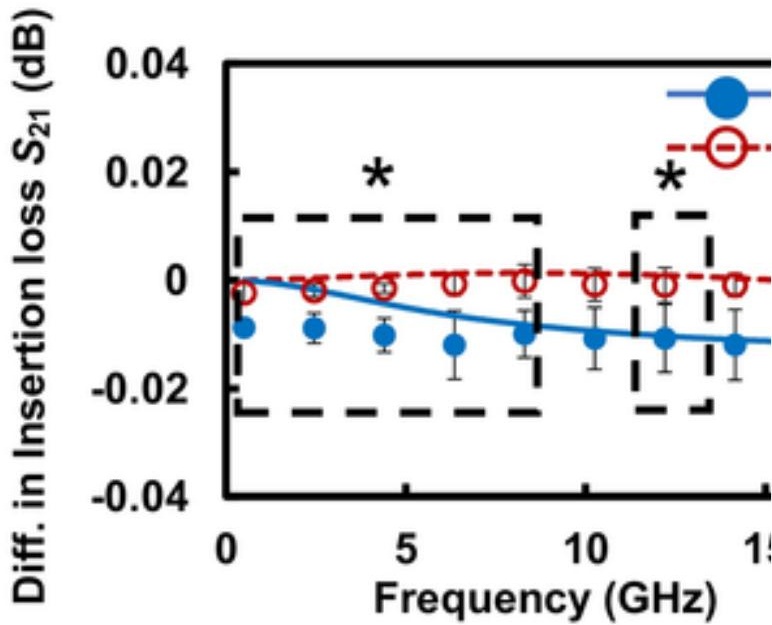

(b)

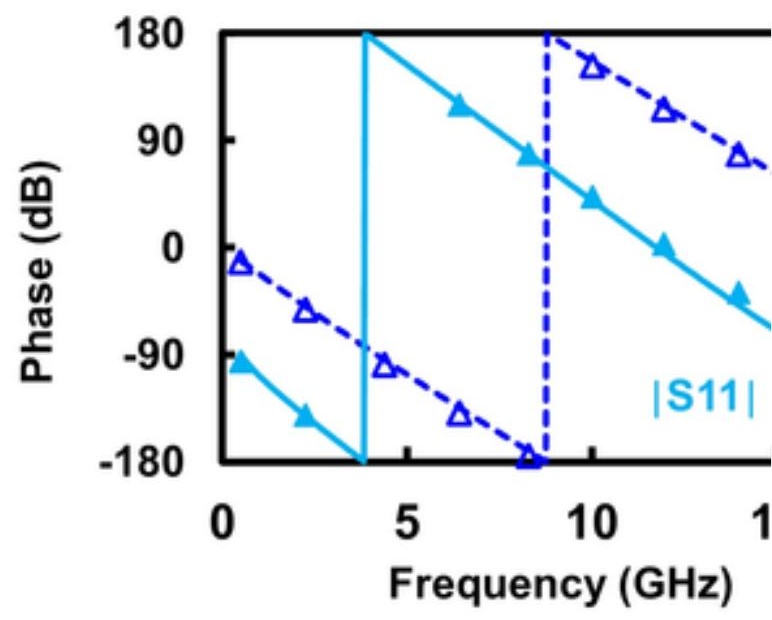

(d) 
Figure. 3 Differences from the background signals in (a) return loss $\left(\Delta\left|S_{11}\right|\right)$ and (b) insertion loss $\left(\Delta\left|S_{21}\right|\right)$ with live and dead E. coli bacteria. The dots are experimentally measured averages and error bars are standard deviations from 3 independent experiments. The dash lines are from circuit modeling. * i Indicates significant differences between live and dead cell signals with $p<0.05$ by Student's $t p \leq 0.05$ by Student's $t$-test. (c, d) The measured (dots and error bars, $n \underline{n}=3$ ) and simulated (dash lines) magnitudes and phases of $\left|S_{11}\right|$ and $\Delta\left|S_{21}\right|$ of LB media.

\subsection{Circuit model and extraction of conductivity and permittivity of single $E$. coli cells}

The equivalent circuit of Fig. 2-(c) was implemented in Keysight ADS circuit simulator initially with estimated parameter values. Then, then the $S \underline{S}$-parameters simulated by using the equivalent circuit were compared with the measured raw spectra and the parameter values iteratively adjusted for the optimum fit between simulated and measured parameters. The device parameters, solution parameters and cell parameters were deembeded stepwise. The dash lines in Fig. 3(c, (c) and (d) illustrate the optimized fit for SS-parameters of LB media without bacteria, while the individual data points in Fig. 3 (c, (c) and (d) are from experimental measurements. The accuracy between measurement data and simulation data is $>-99.50 \%$. A gradient optimizer was used to minimize the least-squares error function defined by the difference between the measured and modeled drifts with respect to the reference scattering parameters within $0.01 \mathrm{~dB}$, which matches the current vector network analyzer accuracy. The dash line-Fig. $3(a, b)$ representss in Fig. 3(a) and (b) represent the difference of fitting LB media with and without whole bacterial cells in the device. With the current parameters extraction approach the membrane capacitance value is of the order of hundreds of $\mathrm{fF}$ at low frequency which is in agreement with literature values and is rapidly shorted by $\mathrm{GHz}$ range signals.

The extracted model parameters from on chip measurements are visible in Table 1 and point at smaller electrical impedance for the live bacteria than for the dead ones. This happens mainly through the detected decrease in conductivity of the dead bacteria suspension and results in increase of energy dissipation (more negative $\left|S_{21}\right|$ ). A somehow higher permittivity value can also be invoked to reproduce the reduced impedance and more positive $\left|S_{11}\right|$ in live cells, although the variability in the detected return loss response impairs extraction of the permittivity parameter. It should be noticed that the membrane parameters contribute little to the observed $S$-parameter difference from bacteria viability and cannot be extracted with great accuracy, because the low fractional volume makes their contribution to the mixture properties negligible in the present frequency range. Large differences in the model parameters result in small variation of the curves because the membrane volume is very small.

Table 1 Dimension and Electrical Properties of Different Celectrical properties of different components.

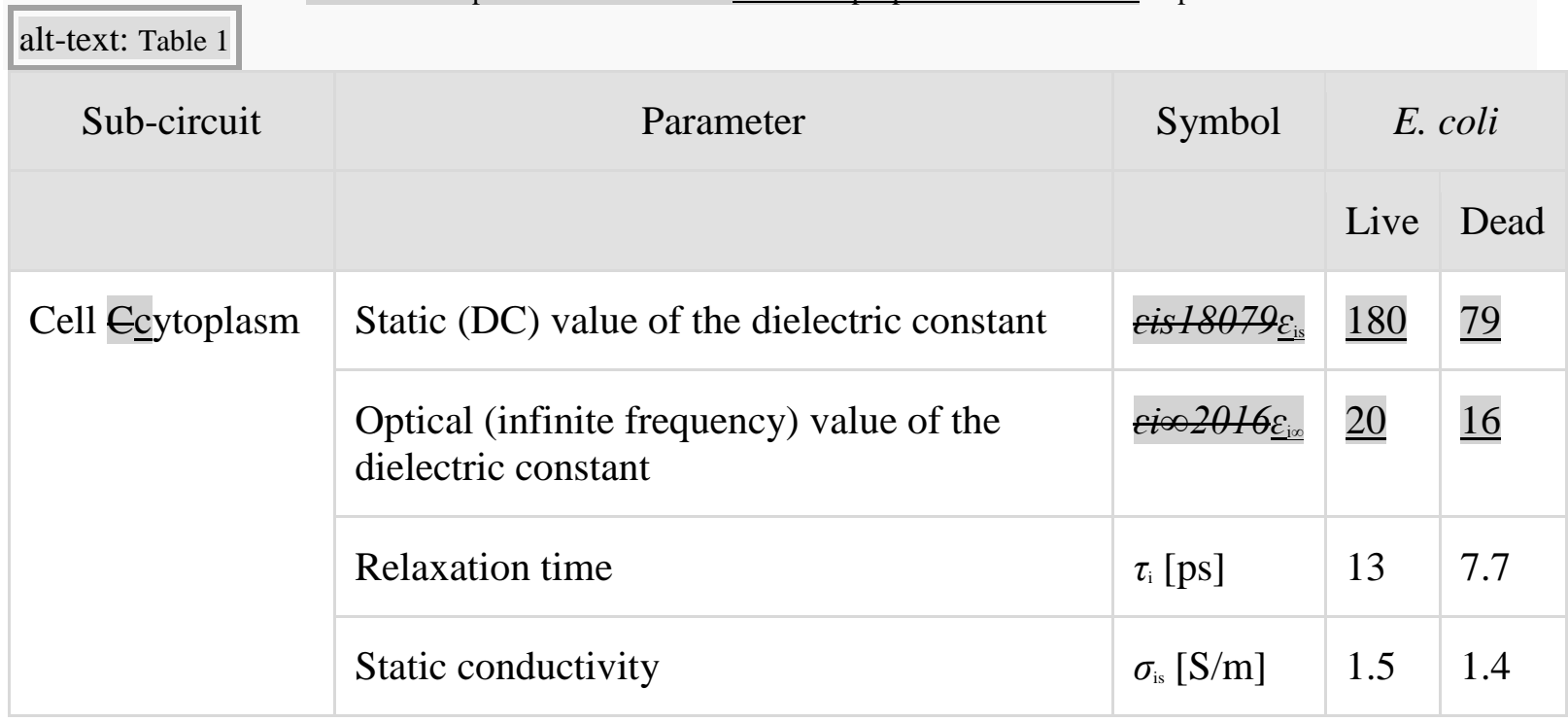




\begin{tabular}{|c|c|c|c|}
\hline Sub-circuit & Parameter & Symbol & E. coli \\
\hline & & & Live Dead \\
\hline \multirow[t]{4}{*}{ Cell Mmembrane } & Static (DC) value of the dielectric constant & $\varepsilon_{\text {mems }}$ & 13 \\
\hline & $\begin{array}{l}\text { Optical (infinite frequency) value of the } \\
\text { dielectric constant }\end{array}$ & $\varepsilon_{\text {mem } \infty}$ & 5 \\
\hline & Relaxation time & $\tau_{\text {mem }}[\mathrm{s}]$ & $1 \times 10^{+4-14}$ \\
\hline & Static conductivity & $\sigma_{\text {mems }}[\mathrm{S} / \mathrm{m}]$ & $1 \times 10^{-5}$ \\
\hline \multirow[t]{4}{*}{ Medium } & Static (DC) value of the dielectric constant & $\varepsilon_{\mathrm{ms}}$ & 79 \\
\hline & $\begin{array}{l}\text { Optical (infinite frequency) value of the } \\
\text { dielectric constant }\end{array}$ & $\varepsilon_{\mathrm{m} \infty}$ & 11 \\
\hline & Relaxation time & $\tau_{\mathrm{m}}[\mathrm{ps}]$ & 9.9 \\
\hline & Static conductivity & $\sigma_{\mathrm{ms}}[\mathrm{S} / \mathrm{m}]$ & 1 \\
\hline \multirow[t]{2}{*}{ Mixture } & $\begin{array}{l}\text { Fractional Volume } \varphi 0.05 \text { Geometric factor- } \\
(\mathrm{R}+\mathrm{d}) / \text { Rvolume }\end{array}$ & $\varphi$ & $\underline{0.05}$ \\
\hline & $\underline{\text { Geometric factor }-(R} \pm \underline{d) / R}$ & $\psi$ & 1.004 \\
\hline \multirow{3}{*}{$\begin{array}{l}\text { CPW: } \\
\text { metal + air }\end{array}$} & Char. Impedance & $Z_{0}[\Omega]$ & 47 \\
\hline & Length@3 GHz & $\theta_{0}\left[^{\circ}\right]$ & 7.4 \\
\hline & Parasitics & $R_{01}[\Omega]$ & 868 \\
\hline \multirow[t]{2}{*}{ CPW: PDMS } & Char. Impedance & $Z_{1}[\Omega]$ & 32 \\
\hline & Length@3 GHz & $\theta_{1}\left[^{\circ}\right]$ & 3.6 \\
\hline
\end{tabular}

\subsection{Conductivity and dielectric permittivity of $E$. coli lysate}

To verify the prediction from the circuit model, both live and dead $E$. coli at $\mathrm{OD}=3.0$ were lysed and the lysate conductivity and permittivity were measured using commercial probes. The lysate from live $E$. colihas significant higher conductivity $(11.93 \pm 0.20 \mu \mathrm{S} / \mathrm{cm})$ compared with that from dead $E$. $\operatorname{coli}(10.92 \pm 0.27 \mu \mathrm{S} / \mathrm{cm})$. Converting the conductivity to ions contributed by single $E$. coli cells, the cytoplasmic ion concentration is estimated to be equivalent to $67.36 \pm 1.13 \mathrm{mM}$ and $61.65 \pm 1.52 \mathrm{mM}$ of potassium chloride in live and heat-killed E. coli, respectively. Such ion concentrations are lower than the reported cytoplasmic ion concentration of $300 \mathrm{mM}$ [60]. It should be noted that the circuit model predicts $6.67 \%$ change of cytoplasmic conductivity, from $1.5 \mathrm{~S} / \mathrm{m}$ in live E. coli to $1.4 \mathrm{~S} / \mathrm{m}$ in dead E. coli. The measured lysate conductivity drop of $8.22 \%$ is comparable with in situ cell measurements. In comparison, the conductivity of LB medium was measured to be $1.04 \pm 0.05 \mathrm{~S} / \mathrm{m}$ in this work, lower than the predicted 
cytoplasmic conductivity of live E. coli. Thus, the dead cells are expected to loss ions to the medium, leading to a drop of the cytoplasmic conductivity.

On the other hand, little difference was observed of the lysate dielectric permittivity between live and dead $E$. coli in the frequency range of $0.5-20 \mathrm{GHz}$ (Fig. 4). This is likely a result of cytoplasmic components being greatly diluted in the lysate: the volume fraction of cells is less than $0.2 \%$ in the culture stspension,while water has a great permittivity compared to biomolecules, masking contribution from the cellular components. We thus inspected properties of the cytoplasmic compartment in alternative means, as described below.

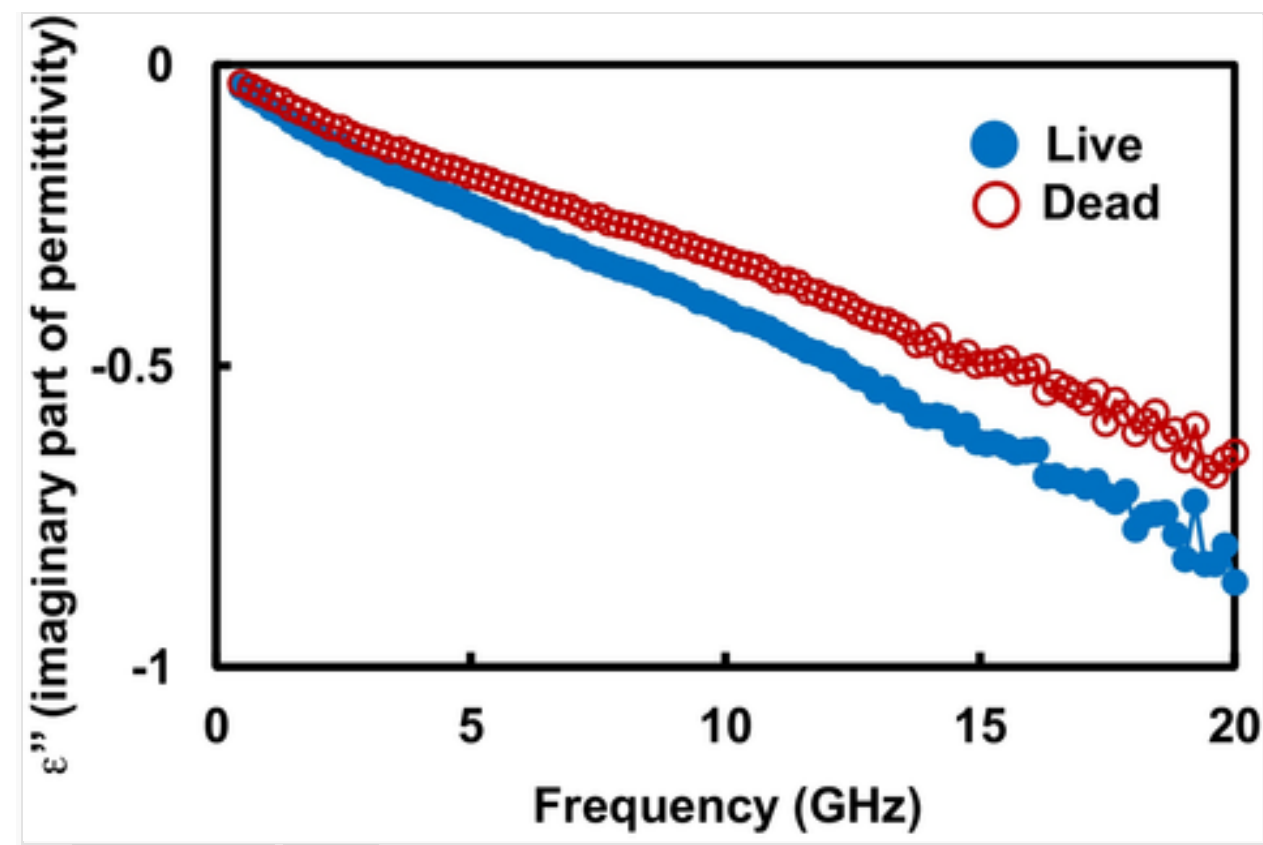

Figure 4The $\varepsilon_{.} 4$ The $\varepsilon^{\prime \prime}$ or imaginary part of permittivity of live and dead E. coli lysate over the frequency range of $500 \mathrm{MHz}-20 \mathrm{GHz}$ measured by a dielectric probe.

\subsection{Diffusion of green fluorescence protein (GFP) in the cytoplasm}

To evaluate compactness of the cytoplasm, fluorescence recovery after photobleaching (FRAP) was used to estimate the diffusivity of intracellular GFP. The rationale behind this test is that dielectric property is greatly influenced by the makeup and organization of polar molecules instead of ion concentration in the microwave frequency range [41,42]. At the same time, cytoplasmic crowdedness, macromolecule composition and organization are influenced by the metabolic state of the cells [61] and are reflected by molecular diffusivity. Fig. 5(a)(a) demonstrates the dynamic change of GFP fluorescence intensity before, during and after photobleaching within a typical $E$. coli cell. The extracted diffusivity of GFP areis summarized in Fig. 5-(b), where individual measurements are shown as dots with the average and standard deviation of each group overlaid on top. The diffusivity values are found to have a narrower distribution for live $E$. coli, which is understandable considering homeostasis in live organisms. The diffusivity for dead E. coli is slightly shifted toward greater values, while the differences between the two groups are not significant. Greater average of the GFP diffusivity in dead E. coli suggests less crowded cytoplasmic environment, likely due to the leakage of macromolecules and relaxation of the cell wall. Such a biochemical change could contribute to the difference of permittivity between the cytoplasm of live and dead cells, which further leads to the $\left|S_{11}\right|$ difference. 


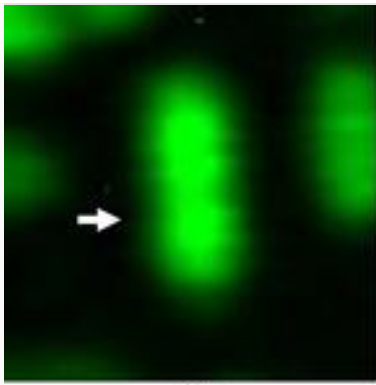

(i)

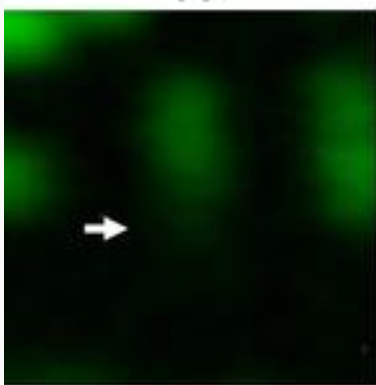

(iv)

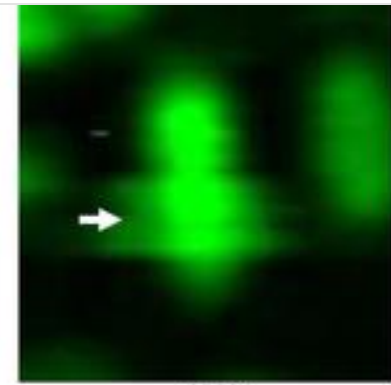

(ii)

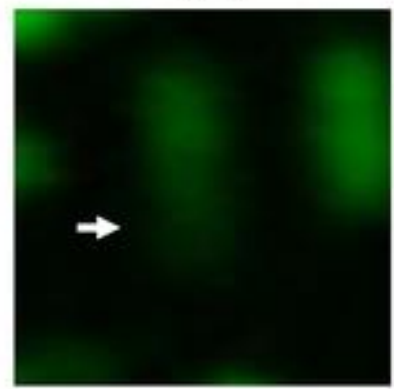

(v)

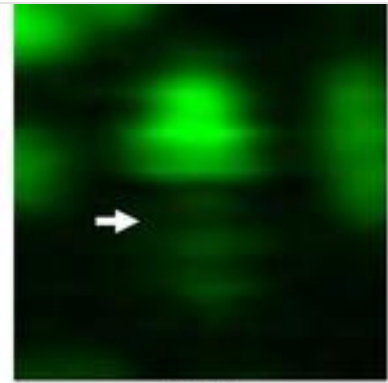

(iii)

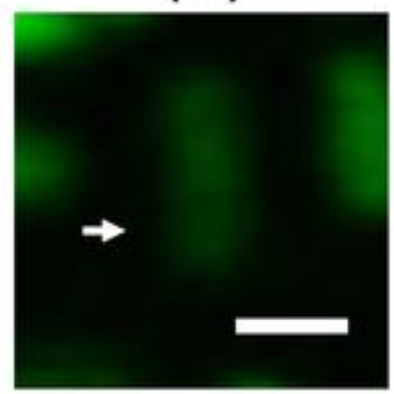

(vi)

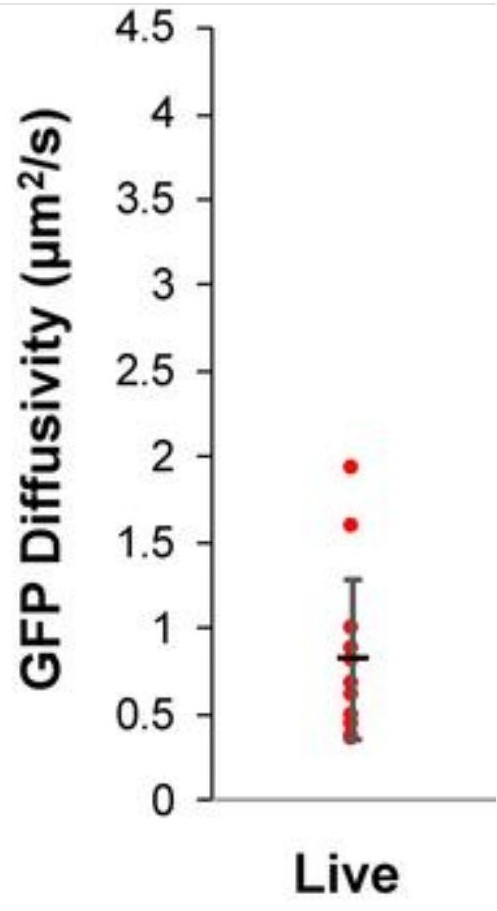

(b)

(a)

Figure. 5 Measurements of GFP diffusivity in E. coli by fluorescence recovery after photobleaching (FRAP). (a) Representative images showing fluorescence intensity change within one $E$. coli cell (indicated by the white arrow) before and after photobleaching, which was used for the extraction of GFP diffusivity. Scale bar $=1 \mu \mathrm{m}$. (i) before photobleaching; (ii, iii) during photobleaching; (iv , _vi) fluorescence recovery. (b) GFP diffusivity in live and dead E. coli measured from at least 10 cells of each type.

\section{Discussion}

Dielectric properties of different cell compartments can be characterized at different frequencies. At lower frequencies from $\mathrm{kHz}$ to $\mathrm{MHz}$ where $\beta$-dispersion occurs, membrane polarization is characterized [62]. At frequencies in the $\mathrm{GHz}$ range, $\gamma$-dispersion is obvious and electrical properties of the cytoplasm are measured. Therefore, compared to sensing at discrete frequencies, broadband electrical detection can yield a wealth of information. As shown in our study, in the frequency range of $0.5 \mathrm{GHz}$ $20 \mathrm{GHz}$, membrane and cytoplasmic properties are extracted simultaneously.

Previously, we showed the identification of single live and dead mammalian cells based on impedance detection in the microwave frequency range [56,63-65]. Translating the sensing technique to bacterial detection presents additional challenges, in particular smaller volume fraction occupied by the target cells at the detection zone. This is achieved by stabilizing the background signal until drift is at the $0.001 \mathrm{~dB}$ per 30-mintte level. In addition, repeated and sequential measurements with and without $E$. coli allow minute background drift to be subtracted. We demonstrate that insertion loss $\left|S_{21}\right|$ signals are different between 15 of live vs. dead $E$. coli cells in the frequency range of $0.5 \mathrm{GHz}-20 \mathrm{GHz}$, and the difference in on the order of $0.01 \mathrm{~dB}$. In comparison, $\left|S_{21}\right|$ difference between single live and dead mammalian cells areis on the order of $0.1 \mathrm{~dB}$ [64]. Considering that the volume of mammalian cells is about two to three orders of magnitude greater than that of $E$. coli, the order of magnitude change in $S$-parameters is reasonable. What's more, dead $E$. coliyields similar $\left|S_{11}\right|$ and $\left|S_{21}\right|$ signals to the background, while signals from live bacteria deviate from the background (Fig. $3-\mathrm{a}, \mathrm{b}(\mathrm{a})$ and (b)). Such a 'digital' response allows easy detection of live microorganisms without standard curves or calibration samples. This is especially significant in resource limited settings where simple procedure and fast detection speed is essential. The other factor that 
benefits point-of-need analysis is the capability to perform measurements in the culture media that has a high conductivity. This is made possible since ion conduction in physiological solutions diminishes [41-44] at gigahertz frequencies. Characterizing cells in their native growth environment saves sample preparation which is often prohibitive at the point of need. It also minimizes perturbation of the cell physiology upon exposure to a different solution.

To understand the source of the $S$-parameter difference between live and dead E. coli, circuit modeling was carried out. Enforcing frequency dependent permittivity and conductivity allows accurate parameter extraction for both the device and the biosample under test over a broader frequency range than by frequency independent models [56]. Frequency independent models do not allow to match the $\varepsilon \varepsilon^{\prime \prime}$ nonmonotone behavior around $2 \mathrm{GHz}$ (they result in a linear fit as opposed to the knee-shaped curve in Fig. S2) and therefore result in more inaccurate parameter extraction in the transition region, where the membrane capacitance is largely (but not completely) bypassed by the microwave signal. It should be noticed that the theoretical mixture model matches the broadband measurement of the cell-free media obtained using a commercial dielectric probe between 0.5 and $20 \mathrm{GHz}$ (Fig. S2). Further strives to take into account the rodshaped bacteria configuration and finite boundaries for the suspension medium could result in even more accurate parameter extraction, but entail significantly increased computational efforts.

Extracted parameters from the model suggest contributions from both cytoplasmic conductivity and permittivity. The cytoplasmic conductivity drop is understandable as dead E. coli cells eventually equilibrate their cytoplasmic ion species with the environment. It has been reported previously that $\mathrm{K}^{+}, \mathrm{Mg}^{2+}$ and $\mathrm{Ca}^{2+}$ efflux from cells during apoptosis [66] or heat induced cell death [67]. Additionally, total concentration of cytoplasmic ions in E. coli has been found to be as high as $\sim 300 \mathrm{mM}$ [60], while the ion concentration in LB media is lower. In particular, $\mathrm{K}^{+}$concentration in the cytoplasm and LB media differs the most. Thus, the conductivity decrease after cell death is most likely due to efflux of $\mathrm{K}^{+}$from the cytoplasm. Measurements of the $E$. coli lysate conductivity, which decreases by $\sim 8.22 \%$ after $E$. coli death, provide direct evidence to support the modeling prediction of cytoplasmic conductivity drop upon heat-induced $E$. coli death, although washing cells in salt free solutions prior to lysis could contribute to some of the ion loss in dead cells as well. It should be noted that the extracted parameters reflect the sample preparation procedures. In fact, Grenier's group reported increase of the cytoplasmic conductivity of dead mammalian cells [68], due to greater ion concentration in the media than in the cytosol. Our result is not contradictory; instead both results demonstrate that cytoplasmic conductivity is indeed measurable by microwave dielectric sensing.

The $E$. coli lysate permittivity shows little difference between live and dead E. coli, since cell components are greatly dilute in the lysate and water molecules are the main contributor to the permittivity of a dilute solution. Alternatively, we examined the 'crowdedness' in the cytoplasm in situ, which shed insights about the hydration environment, molecular polarizability and concentration of organic components. In the microwave range, dispersion from ion movement is greatly dampened, while permittivity is greatly controlled by molecular polarization. Through in situ measurements, we found the diffusivity of GFP in live and heat-killed E. coli was $0.76 \pm 0.45 \mu \mathrm{m}^{2} / \mathrm{s}$ and $1.17 \pm 1.07 \mu \mathrm{m}^{2} / \mathrm{s}$ (Fig. 5), respectively, on the same order as values reported in the literature [69]. The increase of mean GFP diffusivity in dead $E$. coli indicates that cytoplasm of dead E. coli is less compact, which could result from leakage of macromolecules or swelling of cells. In fact, $10 \mathrm{~nm}$ gold nanoparticles were found to easily penetrate the membrane of heat-killed dead $E$. coli (Fig. S3). Thus organic molecules $<10 \mathrm{~nm}$ in diameter could diffuse out easily. Organic molecules, such as amino acids have been found to have high static dielectric constants [70]. The loss of these molecules reduces the cytoplasmic permittivity, as the circuit model predicts. Guallar' group presented a molecular mechanical model to predict the dielectric constant of prokaryotic cytosol of E. coli, containing proteins, metabolites and monatomic ions [71]. Based on the simulation results, the cytosolic dielectric constant changes with its composition and increases significantly with protein concentration. Thus, reduction of the cytoplasmic permittivity upon cell death could also be a result of protein loss. It should be noted that although the model predicts a greater change of the static dielectric constant than conductivity upon $E$. coli death, the energy dissipation term $\left(\left|S_{21}\right|\right)$ better distinguish the $E$. coli vitality than the energy storage term $\left(\left|S_{11}\right|\right)$. This is likely a result of $S$-parameter being more sensitive to the conductivity change in the waveguide configuration used here [64]. Although membrane integrity also differs between live and dead E. coli, the small volume fraction occupied by the membrane limits accurate extraction of the membrane capacitance change, or significant contribution of the membrane electrical parameters to impedance measurements in the microwave range. 
Impedance measurements in the microwave range well complement those in lower frequencies by providing electrical characteristics of different cellular compartment. In the frequency range of megahertz or lower, the membrane capacitance dominates overall cell impedance, thus cell size and membrane integrity is measured [72,73]. Microwave signals easily penetrate the membrane, allowing intracellular properties to be probed [56]. To confirm that electrical difference observed in Fig. 2 is due to intracellular contributions, we included membrane capacitance in the circuit model. However, the simulated $S$-parameters are insensitive to the membrane capacitance, despite an expected change from pore formation: dead E. coli (Fig. S3) presentspores on the order of $10 \mathrm{~nm}$ but not the live ones. Combining these frequencies, a broadband measurement can potentially reveal much richer information than exiting approaches of narrowband detection.

\section{Conclusions}

This work demonstrates that microwave impedance measurements in the frequency range of 0.5 $20 \mathrm{GHz}$ have the sensitivity to discriminate live and dead $E$. coli from a small number of cells. The $\overline{S-}$ parameters from dead $E$. coli are identical those from cell-free media, but live $E$. coli yield measurable difference from the media. Through circuit modeling, electrical measurement of the lysate and other biophysical analysis, the $S$-parameter differences are attributed to decreases of cytoplasmic conductivity and permittivity upon cell death. Since the measurements are performed with whole cells in their native growth environment, our approach is promising for rapid detection of microorganisms and could benefit various applications such as diagnostics, bioterrorism defense and food safety monitoring.

\section{Acknowledgementments}

The project depicted is sponsored by the U.S. Department of Defense, Army Research Office (Grant No. W911NF-14-1-0665) and-W911NF-14-1-0665) and Defense Threat Reduction Agency(Grant No. HDTRA1-12-1-0007 (Grant No. HDTRA1-12-1-0007). The authors also would like to thank Dr. Bryan Berger for the E. coli strain as well as assistance with the culture.

\section{Appendix A. Supplementary data}

Supplementary data associated with this article can be found, in the online version, at http://dx.doi.org/10.1016/j.snb.2017.08.179.

\section{References}

[1] A. Ebrahimi and M.A. Alam, Evaporation-induced stimulation of bacterial osmoregulation for electrical assessment of cell viability, Proc Natl Acad Sci U S A. Natl. Acad. Sci. U.S.A. 2016.

[2] J.W.F. Law, N.S. Ab Mutalib, K.G. Chan and L.H. Lee, Rapid methods for the detection of foodborne bacterial pathogens: principles, applications, advantages and limitations, Front Microbiol. Microbiol. 5, 2015.

[3] H.M. Pan, Y.B. Zhang, G.X. He, N. Katagori and H.Z. Chen, A comparison of conventional methods for the quantification of bacterial cells after exposure to metal oxide nanoparticles, Bme MicrobiolMC Microbiol. 14, 2014.

[4] E.R. Sanders, Aseptic Laboratory Techniques: Plating MethodsJove J Vis Explaboratory techniques: plating methods, JOVE-J. Vis. Exp. 2012.

[5] G.M. Balestra and I.J. Misaghi, Increasing the efficiency of the plate counting method for estimating bacterial diversity, JMicrobiol Meth. Microbiol. Methods 30, 1997, 111-117.

[6] P. Stiefel, S. Schmidt-Emrich, K. Maniura-Weber and Q. Ren, Critical aspects of using bacterial cell viability assays with the fluorophores SYTO9 and propidium iodide, Bme MicrobiolMC Microbiol. 15, 2015.

[7] M.B. Johnson and A.K. Criss, Fluorescence Microscopy Methods for Determining the Viability of Bacteria in Association with Mammalian CellsJove-J Vis Expmicroscopy methods for determining the viability of bacteria in association with mammalian cells, JOVE-J. Vis. Exp. 2013. 
[8] C. Saint-Ruf, C. Cordier, J. Megret and I. Matic, Reliable Detection of Dead Microbial Cells by Using Fluorescent HydrazidesAppl Environ Mierobdetection of dead microbial cells by using fluorescent hydrazides, Appl. Environ. Microbiol. 76, 2010, 1674-1678.

[9] D.B. Schmolze, C. Standley, K.E. Fogarty and A.H. Fischer, Advances in Mierescopy TechniquesArch Pathe1 Lab Medmicroscopy techniques, Arch. Pathol. Lab. Med. 135, 2011, 255-263.

[10] Z. Zhu, W.H. Zhang, X.F. Leng, M.X. Zhang, Z.C. Guan, J.Q. Lu, et al., Highly sensitive and quantitative detection of rare pathogens through agarose droplet microfluidic emulsion PCR at the single-cell level, Lab on a Chip 12, 2012, 3907-3913.

[11] P.B. Lillehoj, C.W. Kaplan, J. He, W.Y. Shi and C.M. Ho, Rapid, Electrical Impedance Detection of Bacterial Pathogens Using Immobilized Antimicrobial PeptidesJala J Lab Automelectrical impedance detection of bacterial pathogens using immobilized antimicrobial peptides, JALA-J. Lab. Autom. 19, 2014, 42-49.

[12] E.W. Kemna, L.I. Segerink, F. Wolbers, I. Vermes and A. van den Berg, Label-free, high-throughput, electrical detection of cells in droplets, Analyst 138, 2013, 4585-4592.

[13] A. Venkatanarayanan, T.E. Keyes and R.J. Forster, Label-Free Impedance Detection of Cancer CellsAnal Chemfree impedance detection of cancer cells, Anal. Chem. 85, 2013, 2216-2222.

[14] K.F. Lei, Review on Impedance Detection of Cellular Responses in Micro/Nanø EnvirenmentMicromachines-impedance detection of cellular responses in micro/nano environment, Micromachines-Basel 5, 2014, 1-12.

[15] R. Ehret, W. Baumann, M. Brischwein, A. Schwinde, K. Stegbauer and B. Wolf, Monitoring of cellular behaviour by impedance measurements on interdigitated electrode structures, Biosens-Bioelectron. Bioelectron. 12, 1997, 29-41.

[16] Y.F. Wu, J.D. Benson and M. Almasri, Micromachined Coulter counter for dynamic impedance study of time sensitive cells, Biomed. Microdevices 14, 2012, 739-750.

[17] Y.F. Wu, J.D. Benson, J.K. Critser and M. Almasri, Note: Microelectromechanical systems Coulter counter for cell monitoring and counting, Rev-Sci Instrum. Sci. Instrum. 81, 2010.

[18] U. Hassan and R. Bashir, Electrical cell counting process characterization in a microfluidic impedance cytometer, Biomed. Microdevices 16, 2014, 697-704.

[19] X. Cheng, Y.S. Liu, D. Irimia, U. Demirci, L.J. Yang, L. Zamir, et al., Cell detection and counting through cell lysate impedance spectroscopy in microfluidic devices, Lab-en a Chip 7, 2007, 746-755.

[20] J. Chen, Y. Zheng, Q.Y. Tan, E. Shojaei-Baghini, Y.L. Zhang, J. Li, et al., Classification of cell types using a microfluidic device for mechanical and electrical measurement on single cells, Lab on a Chip 11, 2011, 3174-3181.

[21] C. Bernabini, D. Holmes and H. Morgan, Micro-impedance cytometry for detection and analysis of micronsized particles and bacteria, Lab en a-Chip 11, 2011, 407-412.

[22] P. Mitra, C.R. Keese and I. Giaever, Electric Measurements Can Be Used to Monitor the Attachment and Spreading of Cells in Tissue-Cmeasurements can be used to monitor the attachment and spreading of cells in tissue-culture, Biotechniques 11, 1991, 504.

[23] C.D. Xiao, B. Lachance, G. Sunahara and J.H.T. Luong, Assessment of cytotoxicity using electric cellsubstrate impedance sensing: Econcentration and time response function approach, Anal-Chem. Chem. 74, 2002, 5748-5753.

[24] J. Wegener, C.R. Keese and I. Giaever, Electric cell-substrate impedance sensing (ECIS) as a noninvasive means to monitor the kinetics of cell spreading to artificial surfaces, Exp-Cell Res. Cell Res. 259, 2000, 158-166.

[25] D. Yamane, Y.C. Wu, T.H. Wu, H. Toshiyoshi, M.A. Teitell and P.Y. Chiou, Electrical impedance monitoring of photothermal porated mammalian cells, JLab Autom. Lab. Autom. 19, 2014, 50-59. 
[26] P.O. Bagnaninchi and N. Drummond, Real-time label-free monitoring of adipose-derived stem cell differentiation with electric cell-substrate impedance sensing, P Natl Acad Sci USA roc. Natl. Acad. Sci. U.S.A. 108, 2011, 6462-6467.

[27] H. Pick, S. Terrettaz, O. Baud, O. Laribi, C. Brisken and H. Vogel, Monitoring proliferative activities of hormone-like odorants in human breast cancer cells by gene transcription profiling and electrical impedance spectroscopy, Biosens Bioelectron. Bioelectron. 50, 2013, 431-436.

[28] I. Voiculescu, F. Li, F. Liu, X.D. Zhang, L.M. Cancel, J.M. Tarbell, et al., Study of long-term viability of endothelial cells for lab-on-a-chip devices, Sensor Actuat B-Chem. Actuators, B: Chem. 182, 2013, 696 705.

[29] J. Muller, C. Thirion and M.W. Pfaffl, Electric cell-substrate impedance sensing (ECIS) based real-time measurement of titer dependent cytotoxicity induced by adenoviral vectors in an IPI-2I cell culture model, Biosens Bioelectron. Bioelectron. 26, 2011, 2000-2005.

[30] C.E. Campbell, M.M. Laane, E. Haugarvoll and I. Giaever, Monitoring viral-induced cell death using electric cell-substrate impedance sensing, Biosens Bioelectron. Bioelectron. 23, 2007, 536-542.

[31] T.M. Curtis, J. Tabb, L. Romeo, S.J. Schwager, M.W. Widder and W.H. van der Schalie, Improved cell sensitivity and longevity in a rapid impedance-based toxicity sensor, JAppl Toxicol. Appl. Toxicol. 29, 2009, 374-380.

[32] L.J. Yang, Y.B. Li, C.L. Griffis and M.G. Johnson, Interdigitated microelectrode (IME) impedance sensor for the detection of viable $\underline{S}$ almonella typhimurium, Biosens BioelectronBiosens. Bioelectron. 19, 2004, 11391147.

[33] J. Suehiro, R. Hamada, D. Noutomi, M. Shutou and M. Hara, Selective detection of viable bacteria using dielectrophoretic impedance measurement method, JElectrestat. Electrostat. 57, 2003, 157-168.

[34] M. Javanmard, H. Esfandyarpour, F. Pease and R.W. Davis, Electrical detection of proteins and DNA using bioactivated microfluidic channels: Ttheoretical and experimental considerations, J Vac Sci Technol. Vac. Sci. Technol. B 27, 2009, 3099-3103.

[35] S. Gawad, K. Cheung, U. Seger, A. Bertsch and P. Renaud, Dielectric spectroscopy in a micromachined flow cytometer: theoretical and practical considerations, Lab-en Chip 4, 2004, 241-251.

[36] T.R. Gowrishankar and J.C. Weaver, An approach to electrical modeling of single and multiple cells, $P$ Natt Acad Sci USAroc. Natl. Acad. Sci. U.S.A. 100, 2003, 3203-3208.

[37] H. Lu, M.A. Schmidt and K.F. Jensen, A microfluidic electroporation device for cell lysis, Lab on a Chip 5, 2005, 23-29.

[38] M. Pavlin, M. Kanduser, M. Rebersek, G. Pucihar, F.X. Hart, R. Magjarevic, et al., Effect of cell electroporation on the conductivity of a cell suspension, Biophys J. J. 88, 2005, 4378-4390.

[39] B. Rubinsky, Irreversible electroporation in medicine, Technol-Cancer Res Treat.Cancer Res. Treat. 6, 2007, 255-260.

[40] J. Yang, J. Vykoukal, J. Noshari, F. Becker, P. Gascoyne, P. Krulevitch, et al., Dielectrophoresis-Based Microfluidic Separation and Detection SystemsInt J Adv Manuf Systbased microfluidic separation and detection systems, Int. J. Adv. Manuf. Syst. 3, 2000, 1-12.

[41] K.R. Foster, J.L. Schepps and B.R. Epstein, Microwave Dielectric Studies on Proteins, Tissues, and Heterogeneous Strspensions, Bdielectric studies on proteins, tissues, and heterogeneous suspensions, bioelectromagnetics, 3, 1982, 29-43.

[42] N. Nandi, K. Bhattacharyya and B. Bagchi, Dielectric relaxation and solvation dynamics of water in complex chemical and biological systems, Chem Rev. Rev. 100, 2000, 2013-2046.

[43] I. Ermolina, H. Morgan, N.G. Green, J.J. Milner and Y. Feldman, Dielectric spectroscopy of Tobacco Mosaic VirusBiochim Biophystobacco mosaic virus, Biochim. Biophys. Acta 1622, 2003, 57-63.

[44] M. Suzuki, J. Shigematsu and T. Kodama, Hydration study of proteins in solution by microwave dielectric analysis, JPhys Chem Us. Phys. Chem.-US 100, 1996, 7279-7282. 
[45] M. Nikolic-Jaric, S.F. Romanuik, G.A. Ferrier, G.E. Bridges, M. Butler, K. Sunley, et al., Microwave frequency sensor for detection of biological cells in microfluidic channels, Biomicrofluidics 3, 2009.

[46] C. Dalmay, M. Cheray, A. Pothier, F. Lalloue, M.O. Jauberteau and P. Blondy, Ultra sensitive biosensor based on impedance spectroscopy at microwave frequencies for cell scale analysis, Senser Actuat a Phys. Actuators, A: Phys. 162, 2010, 189-197.

[47] D. Dubuc, O. Mazouffre, C. Llorens, T. Taris, M. Poupot, J.J. Fournie, et al., Microwave-based biosensor for on-chip biological cell analysis, Analog Integr-Circ S. Circuits Syst. 77, 2013, 135-142.

[48] M. Lohndorf, U. Schlecht, T.M.A. Gronewold, A. Malave and M. Tewes, Microfabricated high-performance microwave impedance biosensors for detection of aptamer-protein interactions, Appl Phys Lett. Phys. Lett. 87, 2005.

[49] T. Chretiennot, D. Dubuc and K. Grenier, A Microwave and Microfluidic Planar Resonator for Efficient and Accurate Complex Permittivity Characterization of Aqueous Solutionsleee T Microwmicrowave and microfluidic planar resonator for efficient and accurate complex permittivity characterization of aqueous solutions, IEEE Trans. Microwave Theory 61, 2013, 972-978.

[50] K. Grenier, D. Dubuc, T. Chen, F. Artis, T. Chretiennot, M. Poupot, et al., Recent Advances in MicrowaveBased Dielectric Spectroscopy at the Cellular Level for Cancer Iadvances in microwave-based dielectric spectroscopy at the cellular level for cancer investigations, Ieee T MicrowEEE Trans. Microwave Theory 61, 2013, 2023-2030.

[51] K. Grenier, D. Dubuc, P.E. Poleni, M. Kumemura, H. Toshiyoshi, T. Fujii, et al., Integrated Broadband Microwave and Microfluidic Sensor Dedicated to Bbroadband microwave and microfluidic sensor dedicated to bioengineering, Ieee T MicrowEEE Trans. Microwave Theory 57, 2009, 3246-3253.

[52] T. Chen, F. Artis, D. Dubuc, J.J. Fournié, M. Poupot and K. Grenier, Microwave biosensor dedicated to the dielectric spectroscopy of a single alive biological cell in its culture medium, In: 2013 IEEE MTT-S International Microwave Symposium Digest (MTT), 2013, 1-4.

[53] F. Artis, D. Dubuc, J.J. Fournié, M. Poupot and K. Grenier, Microwave dielectric spectroscopy of cell membrane permeabilization with saponin on human B lymphoma cells, In: 2014 IEEE MTT-S International Microwave Symposium (IMS2014), 2014, 1-4.

[54] B. Sadou, O. Zemb, D. Dubuc, K. Grenier and F. Moutier, Développement d'un biocapteur radiofréquence pour la détection de prolifération bactérienne, In: Journées Nationales Micro-ondes 2017, Saint-Malo, France2017.

[55] T. Sun, S. Gawad, N.G. Green and H. Morgan, Dielectric spectroscopy of single cells: time domain analysis using Maxwell's mixture equation, JPhys D Appl Phys. Phys. D: Appl. Phys. 40, 2007, 1-8.

[56] Y.Q. Ning, C. Multari, X. Luo, C. Palego, X.H. Cheng, J.C.M. Hwang, et al., Broadband Electrical Detection of Individual Biological Cellsteee T Mierowelectrical detection of individual biological cells, IEEE Trans. Microwave Theory 62, 2014, 1905-1911.

[57] D.A. Siegele and J.C. Hu, Gene expression from plasmids containing the araBAD promoter at subsaturating inducer concentrations represents mixed populations, P Natl Acad Sci USA roc. Natl. Acad. Sci. U.S.A. 94, $1997,8168-8172$.

[58] S. Singh, M.S. Giridhar, C.V.N. Rao, S. Bhalke and R. Islam, Planar architecture for microstrip interfaced packaging of coplanar-waveguide-based radio frequency microelectromechanical system switches, MOEMS 14, 2015, 15002.

[59] C.-Y. Lin, C.-C. Hsu and C.-L. Dai, Fabrication of a Mieromachined Capacitive Switeh Using the CMOSMEMS Tmicromachined capacitive switch using the CMOS-MEMS technology, Micromachines __Basel 6, 2015, 1447.

[60] F.X. Theillet, A. Binolfi, T. Frembgen-Kesner, K. Hingorani, M. Sarkar, C. Kyne, et al., Physicochemical Properties of Cells and Their Effects on Intrinsically Disordered Proteins (IDPs)Chemical Reviewscells and their effects on intrinsically disordered proteins (IDPs), Chem. Rev. 114, 2014, 6661-6714.

[61] J.T. Trevors, J.D. van Elsas and A.K. Bej, The Molecularly Crowded Cytoplasm of Bacterial Cells: Dividing Cells Contrasted with Viable but Non-culturable (VBNC) Bacterial CellsCurr Issues Mol Biolmolecularly 
crowded cytoplasm of bacterial cells: dividing cells contrasted with viable but non-culturable (VBNC) bacterial cells, Curr. Issues Mol. Biol. 15, 2013, 1-6.

[62] R. Bashir, BioMEMS: state-of-the-art in detection, opportunities and prospects, Adv Drug Deliv Rev. Drug Delivery Rev. 56, 2004, 1565-1586.

[63] X. Ma, X. Du, C.R. Multari, Y. Ning, X. Luo, V. Gholizadeh, et al., Reproducible broadband measurement for cytoplasm capacitance of a biological cell, In: 2016 IEEE MTT-S International Microwave Symposium (IMS), 2016, 1-4.

[64] X. Ma, X. Du, C.R. Multari, Y. Ning, C. Palego, X. Luo, et al., Broadband single-cell detection with a coplanar series gap, In: Microwave Measurement Conference, 2015 86th ARFTG2015, 1-3.

[65] A. Denzi, C. Merla, C. Palego, A. Paffi, Y. Ning, C.R. Multari, et al., Assessment of cytoplasm conductivity by nanosecond pulsed electric fields, IEEE Trans-Biomed Eng. Biomed. Eng. 62, 2015, 1595-1603.

[66] H.J. Mulhall, A. Cardnell, K.F. Hoettges, F.H. Labeed and M.P. Hughes, Apoptosis progression studied using parallel dielectrophoresis electrophysiological analysis and flow cytometry, Integr-Biol Uk. Biol.$\underline{U K}$ 7, 2015, 1396-1401.

[67] F.H. Grau, Significance of the inactivation of transport in thermal death of Escherichia coliAppl Environ MicrobiolEscherichia coli, Appl. Environ. Microbiol. 36, 1978, 230-236.

[68] T. Chen, D. Dubuc, M. Poupot, J.J. Fournié and K. Grenier, Broadband discrimination of living and dead lymphoma cells with a microwave interdigitated capacitor, In: 2013 IEEE Topical Conference on Biomedical Wireless Technologies, Networks, and Sensing Systems, 2013, 64-66.

[69] J.T. Mika, V. Krasnikov, G. van den Bogaart, F. de Haan and B. Poolman, Evaluation of pulsed-FRAP and conventional-FRAP for determination of protein mobility in prokaryotic cells, PLoS OneNE 6, 2011, e25664.

[70] J.C. Shepherd and E.H. Grant, Dielectric Properties of Amino Acid Solutions .I. Dielectric Dispersion in Aqueous Epsilon-Aminocaproic Acid SolutionsProc R Soc Lon Ser-properties of amino acid solutions .i. dielectric dispersion in aqueous epsilon-aminocaproic acid solutions, Proc. R. Soc. London Ser. A 307, $1968,335$.

[71] B.P. Cossins, M.P. Jacobson and V. Guallar, A new view of the bacterial cytosol environment, PLoS ComputBiol. Biol. 7, 2011, e1002066.

[72] S.M. Wu, W.W. Ye, M. Yang, M. Taghipoor, R. Meissner, J. Brugger, et al., Impedance sensing of DNA immobilization and hybridization by microfabricated alumina nanopore membranes, Senser Actuat BChem. Actuators, B: Chem. 216, 2015, 105-112.

[73] Q.Y. Tan, G.A. Ferrier, B.K. Chen, C. Wang and Y. Sun, Quantification of the specific membrane capacitance of single cells using a microfluidic device and impedance spectroscopy measurement, Biomicrofluidics 6, 2012.

Hang Li received his B.S degree in chemical engineering and technology from Xi'an Shiyou University, Xi'an, China, in 2009, and the Ph.D. degree in chemical and biomolecular engineering from The University of Akron, OH, USA, in 2015. Since 2015, he has been a Postdoctoral Research Associate with Lehigh University, Bethlehem, PA. His research interest includes mammalian cell electroporation and cell/bacterial membrane dynamic detection by broadband sensing.

Caroline Multari received the B.A. degree in biochemistry from Case Western Reserve University, Cleveland, OH, USA, in 2005, and the M.S. degree in materials engineering from California State University, Northridge, CA, USA, in 2011. Her doctoral research is focused on point-of-care microfluidic biosensors and developing polymeric biomaterials for bioparticle capture.

Cristiano Palego received the M.S. degree in electrical engineering from the University of Perugia, Perugia, Italy, in 2003, and the Ph.D. degree in microwave engineering and optoelectronics from the University of Limoges, Limoges, France, in 2007. He is currently a Senior Lecturer of smart sensors and instrumentation with Bangor University, Gwynedd, U.K., and a Visiting Research Scientist with Lehigh University, Bethlehem, PA, USA. He has been a Postdoctoral Research Associate (2007 2010) and a Research Scientist (2010 present) with Lehigh University. He was a Research Scientist with Lehigh University (2010-2017) and is currently a Senior Lecturer in smart sensors and instrumentation at Bangor University, U.K. His interests include electromagnetic theory, microtechnology/nanotechnology and 
biomedical research, as well as RF microelectromechanical systems (RF-MEMS) for reconfigurable frontends, antenna arrays, and high-power applications.

Xiao Ma received the B.S. degree in physics from Peking University, China in 2014. He is currently working towards his Ph.D. degree at Lehigh University. In the summer of 2013, he worked as a research assistant at Georgia Tech Lorraine on BIMDM structures. Now his research interest includes biosensor, microwave measurement and liquid calibration. He is specialized in 3D electromagnetic simulation using finite element methods and microwave device characterization techniques.

Xiaotian Du received his B.S. degree in materials science from Fudan University, Shanghai, China in 2016. In 2014, He was exchanging in UC Berkeley. Since July of 2015, he has been working as a research assistant in electrical engineering at Lehigh University, Bethlehem, PA. And he will start pursuing his $\mathrm{Ph} . \mathrm{D}$. degree in electrical engineering at Lehigh University, Bethlehem, PA, in the fall of 2016. His research interest includes biosensors, MEMS and other microwave devices and circuits.

Yaqing Ning received her B.S. degree in electrical engineering from Shanghai Jiao Tong University, China in 2010 and $\mathrm{PhD}$ degree in electrical engineering from Lehigh University in 2015. During 2012, she worked as a summer intern at RF Micro Devices Inc. on device modeling and electromagnetic simulation for linearity improvement through RF characterization. She is involved in researches on RF MEMS capacitive switches and phase shifters, as well as biomedical devices for detection purposes. She is specialized in 3D electromagnetic simulation using finite element methods. She is currently a senior engineer at Huawei Technologies Co., Pudong, Shanghai, China.

Javier Buceta received his B.S. and M.Sc. in Physics from Complutense University, Madrid, Spain, in 1994, and his PhD in Physics from UNED University in 2000 (Madrid, Spain). After a postdoctoral stay at University of California San Diego (2001-2004) he joined the Barcelona Science Park as a PI within the Computer Simulation and Modeling Unit. In 2014 he joined Lehigh University (Bioengineering Department and Chemical and Biomolecular Engineering Department) where he is currently an associate professor. The focus of his research is Biophysical and Systems Biology approaches towards the understanding of collective cell behavior.

James C. M. Hwang received the B.S. degree in physics from National Taiwan University, Taipei, Taiwan, and the M.S. and Ph.D. degrees in materials science and engineering from Cornell University, Ithaca, New York. Since 1988, he has been Professor of Electrical Engineering and Director of Compound Semiconductor Technology Laboratory at Lehigh University, Bethlehem, Pennsylvania. Prior to that, he spent twelve years at IBM, Bell Labs, GE, and GAIN. He cofounded GAIN and QED; the latter became a public company (IQE). He has worked on microwave materials, devices and circuits for four decades.

Xuanhong Cheng received her B.S. in biology from Wuhan University, China in 1998, M.S. in electrical engineering and $\mathrm{PhD}$ in bioengineering from University of Washington in 2004. After postdoctoral training in the Department of Surgery at Massachusetts General Hospital, she joined Lehigh University in 2008 where she is currently an associate professor in the Bioengineering Program and Department of Materials Science and Engineering. The focus of her research is to develop microfluidic devices for cell and pathogen analysis. In combination with nanomaterials and biosensors, these devices are expected to perform automated sample processing and sensitive analyte detection towards point-of-care uses. 